\title{
MIDLINE DIASTEMA: TREATMENT OPTIONS
}

Sunil Kumar L.N, Pradnya Nagmode, Varsha Tambe, Sumeet Gonmode, Fareedi Mukram Ali

1. Reader, Department of Orthodontics and Dentofacial Orthopedics, S. M. B. T. Dental College and Hospital, Sangamner.

2. Reader, Department of Conservative Dentistry and Endodontics, S. M. B. T. Dental College and Hospital, Sangamner

3. Post Graduate Student, Department of Conservative Dentistry and Endodontics, S. M. B. T. Dental College and Hospital, Sangamner.

4. Senior Lecturer, GDC, Mumbai.

5. Reader, Dept of Oral \& Maxillofacial Surgery, S. M. B. T. Dental College and Hospital, Sangamner

\section{CORRESPONDING AUTHOR}

Fareedi Mukram Ali, Reader, Dept of Oral \& Maxillofacial Surgery, SMBT Dental College, Sangamner Taluka, Ahmednagar Dist, Maharashtra State

E-mail: faridi17@rediffmail.com, Ph: 00919326325156.

ABSTRACT: Maxillary midline diastema is a common esthetic problem in mixed and permanent dentition. The space can occur either as a transient malocclusion or created by developmental, pathological or iatrogenic factors. Many innovative therapies are available from restorative procedures such as composite build-up to surgery (frenectomies) and Orthodontics is available. Treatment depends upon the correct diagnosis of its etiology and early intervention relevant to the specific etiology. Presented herewith case reports which were treated by Orthodontic treatment and also composite build-up.

KEY WORDS: Midline Diastema, Treatment options

INTRODUCTION: A space between adjacent teeth is called a "diastema". Midline diastemata (or diastemas) occur in approximately $98 \%$ of 6 year olds, $49 \%$ of 11 year olds and $7 \%$ of $12-18$ year olds. ${ }^{1}$ The midline diastema of the teeth is often a normal or developmental occurrence, due to the position of the teeth in their bony crypts, to the eruption path of the cuspids, and to the increase in size of the premaxilla at the time of eruption of the maxillary permanent central incisors ${ }^{2}$. Eruption, migration, and physiological readjustment of the teeth, labial and facial musculature, development into the beauty-conscious teenage group, the anterior component of the force of occlusion, and the increase in the size of the jaws with accompanying increase in tonicity of the facial musculature all tend to influence closure of the midline dental space. Since the frenum is considered a problem only if the teeth are separated, the effect of these natural forces is not only to close the midline dental space, but also automatically to eliminate the problem of the frenum. Relatively early in orthodontic literature, the superior labial frenum was listed as a cause of the midline diastema. Frenectomy was advised, and techniques for its removal were described. The number of frenectomies currently recommended by orthodontists is relatively small. Most of the respondents are treating the midline dental space Orthodontically without frenectomy. Often, people have a diastema treated for cosmetic reasons. They may be self-conscious about having a space between their teeth. However, a diastema also can affect speech. In cosmetic treatment, the direct-bonding restoration technique re - presents the preferred therapeutic option. It preserves maximal tooth structure and helps to 
restore function and aesthetics in only a few clinical visits. In addition, the technique is economical and the possible need for sophisticated indirect restoration can be postponed. Direct-bonding restorations demand excellent clinical skills. The clinician is required to incorporate various clinical techniques, tips and tricks.

\section{CAUSES}

- Genetic: midline spacing has a racial and familial background.

- Physiological: midline diastema may be considered normal for many children during the eruption of the permanent maxillary central incisors. When the incisors first erupt, they may be separated by bone and the crowns incline distally because of crowding of the roots. With the eruption of lateral incisors and permanent canines, midline diastema reduces or even closes (ugly duckly stage)

- Supernumerary teeth: The presence of supernumerary teeth and their effect on the developing occlusion has been investigated by numerous authors, but high proportion (38\%) of patients with supernumerary teeth had delayed or failed eruption of permanent teeth, whereas inverted supernumeraries were more likely to be associated with bodily displacement of the permanent incisors, median diastema and torsiversion.

- Abnormal frenum: A maxillary midline diastema is often complicated by the insertion of the labial frenum into the notch in the alveolar bone, so that a band of heavy fibrous tissue lies between the central incisors ${ }^{3}$. A simple test, blanching test was performed for an abnormal high frenum by observing the location of alveolar attachment when intermittent pressure was exerted on the frenum. If a heavy band of tissue with a broad, fan like base is attached to the palatine papillae and produces the blanching of the papilla.

- Tooth material - arch length discrepancy: condition such as missing teeth, microdontia, peg shaped laterals, macrognathia.If the lateral incisors are small or absent, the extra space can allow the incisor teeth to move apart and create a diastema4.

- Habits: Habits such as thumb sucking or tongue thrusting can cause procliantion of teeth, which causes midline diastema along with generalized spacing.

- Midline pathology: soft tissue and hard tissue pathologies such as cysts, tumors and odontomes may cause midline diastema.

- Iatrogenic: rapid maxillary expansion can cause midline diastema due to opening of the intermaxillary suture.

- Moyers stated that imperfect fusion at the midline of premaxilla is the most common cause of maxillary midline diastema. The normal radiographic image of the suture is a Vshaped structure (Fig 1).

LABORATORY ANALYSIS: A functional analysis would need to be done in the diagnostic waxup, and eventually the provisional prototypes, to make sure that the new restorations would be compatible with habitual movements such as those that occur in mastication ${ }^{5}$ and speech. ${ }^{6}$ The steepness of the interarch relationship in the area of the cuspids (along with the type of food) determines to a large degree the path of closure during mastication.7,8

The completed laboratory analysis via the diagnostic equilibration and wax-up provide a great deal of information: 
- The number of restorative units needed to optimally eliminate the patient's dental midline diastema .

- The wax-up illustrated how the individual restorations would appear dimensionally and whether an occlusal/ functional scheme could be worked out that would provide proper force management for longevity of the restorations.

- The wax-up would serve as the prototype design for the direct fabrication of the provisional restorations so that laboratory approximations could be adjusted and verified in vivo

TREATMENT OPTIONS:Before the practitioner can determine the optimal treatment, he or she must consider the contributing factors. These include normal growth and development, toothsize discrepancies, excessive incisor vertical overlap of different causes, mesiodistal and labiolingual incisor angulation, generalized spacing and pathological conditions. ${ }^{9}$ A carefully developed differential diagnosis allows the practitioner to choose the most effective orthodontic and/or restorative treatment. Diastemas based on tooth-size discrepancy are most amenable to restorative and prosthetic solutions. ${ }^{9}$ The most appropriate treatment often requires orthodontically closing the midline diastema.

Treatment of diastema varies and it requires correct diagnosis of its etiology, and early intervention relevant to the specific etiology. Correct diagnoses include radiological and clinical examinations and possibly tooth size evaluation.

- No treatment is usually done, if the diastema is physiological/transient as it spontaneously closes after the eruption of permanent maxillary canines. Spontaneous correction of a childhood diastema is most likely when its width is not more than $2 \mathrm{~mm}$.

- Pathological causes like supernumerary teeth, midline soft tissue anomalies can be removed surgically and spaces are closed orthodontically. Oral habits such as thumb sucking and tongue thrusting should be corrected before closure of the space.

ORTHODONTIC APPROACH: It is an error to surgically remove the frenum at an early age and then delay orthodontic treatment in the hope that the diastema will close spontaneously. If the frenum is removed, while there is still a space between the central incisors, scar tissue forms between the teeth as healing progresses, and a long delay may result in a space that is more difficult to close than it was previously.

It is better to align the teeth before frenectomy. Sliding them together along an arch wire is usually better than using a closing loop, because loop with any vertical height will touch and irritate the frenum.

If the diastema is small, it is usually possible to bring the central incisors completely together before surgery.

If the space is large and frenal attachment is thick, it may not possible to completely close the space before surgical intervention. The space should be closed at least partially and the orthodontic movement to bring the teeth together should be resumed immediately after the frenectomy, so that the teeth are brought together quickly after the procedure. When this is done, healing occurs with the teeth together and the inevitable post-surgical scar tissue stabilizes the teeth instead of creating obstacles to final closure of the space ${ }^{10}$. (Fig 2, Fig 3) 
RETENTION AFTER TREATMENT: permanent retention is required (Fig 4). According to Mulligan, if anterior tooth roots are placed divergent, then there is no need of retention.

ESTHETIC APPROACH: patient demand for aesthetic dentistry with minimally invasive procedures has resulted in the extensive utilization of freehand bonding of composite resin to anterior teeth.

Dental patients are more conscious of their appearances and have raised the importance of the smile within society as a whole; this impacts full mouth restoration as well as more conservative restorative procedures that include class IV restorations, veneers and diastema closure.

The diastema presents itself to the dental office on a regular basis. It may be small or large. The papilla may be long and skinny or blunted. The size will have an effect on what material will be chosen to achieve the desired results. When dealing with a large space closure, orthodontist may be indicated to allow for a more esthetic outcome.

When the teeth are in proper orthodontic alignment, no preparation of the tooth structure is necessary. If there is an alignment problem, minor tooth preparation will be necessary to achieve proper arch form.

Composite resin is an ideal material when restoring diastema closure. It is highly polishable, long lasting and mimics natural tooth structure. It is a conservative alternative to an indirect restoration. (Fig 5)

\section{REFERENCES:}

1. Foster TD, Grundy MC. Occlusal changes from primary to permanent dentitions. J Orthod 1986; 13: 187-93.

2. Edwards JG. The diastema, the frenum, the frenectomy a clinical study. Am J Orthod 1977; 71: 489-508.

3. Kaimenyi JT. Occurance of midline diastema and frenum attachments among school children in Nairobi, Kenya. Indian J Dent Res 1998; 9:67-71.

4. Nainar SM, Gnanasundaram N. Incidence and etiology of midline diastema in a population in south India. Angle Orthod 1989; 59:277-82.

5. Pameijer JHN, Glickman I, Roeber FW. Intraoral occlusal telemetry III. Tooth contacts in chewing, swallowing and bruxism. J Periodont. 1969; 40:253-258.

6. Howell CT. Incisal relationships during speech. J Prosthet Dent. 1986;56: 93-98.

7. Nishagawa K, Nakano M, Bando E. Study of jaw movement and masticatory activity during unilateral chewing with and without balancing side molar contacts. J Oral Rehab. 1997; 24:691-696.

8. Hiiemae K, Heath MR, Heath G, et al. Natural bites, food consistency and feeding behavior in man. Arch Oral Biol. 1996;41: 175-189.

9. Chu FC, Siu AS, Newsome PR, Wei SH. Management of median diastema. Gen Dent. 2001;49(3):282-7.

10. Spilka CJ, Mathews PH. Surgical closure of diastema of central incisors. Am J Orthod 1979; 76:443-7. 


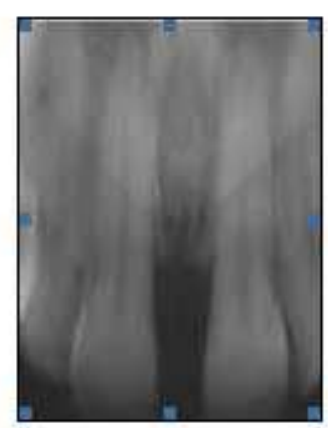

Fig 1

Fig 1. Pathological V-shaped intermaxillary suture.

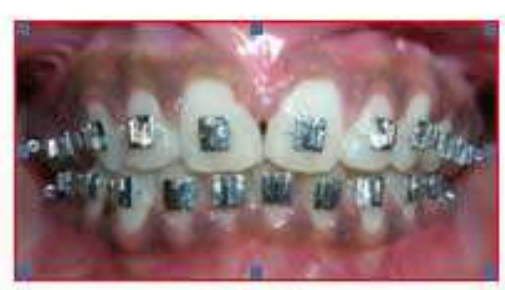

Fig 2(A)

Fig 2(A): Case treated by using Begg's technique :

Post-treatment photographs intermaxillary suture.

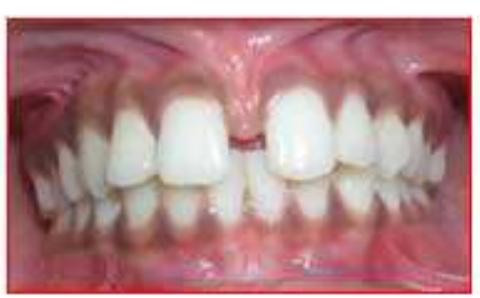

Fig 2.

Fig 2: Case treated by using Begg's technique : Pre-treatment photographs.

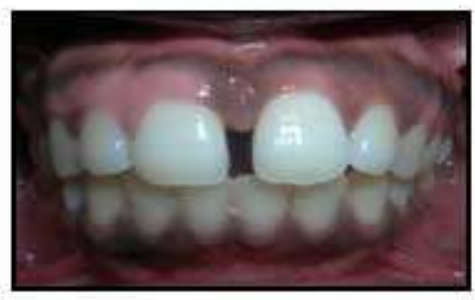

Fig 3

Fig 3: Case treated by using PAE technique : Pre-treatment photographs. 


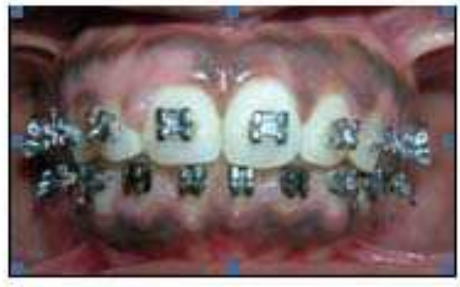

Fig 3(A)

Fig 3(A): Case treated by using PAE technique : Post-treatment photographs.

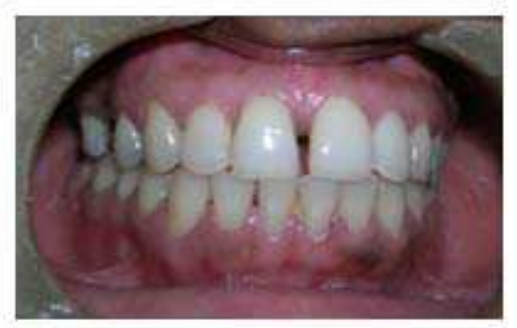

Fig 5

Fig 5(B): Aesthetic approach : Case treated with direct restorative material : Pre-treatment photograph.

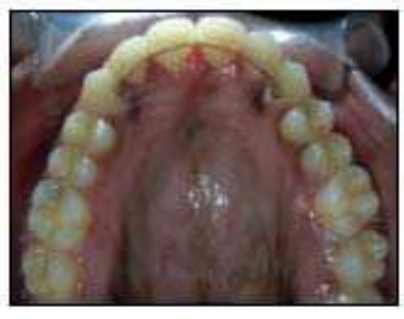

Fig 4

Fig (4). Permanent Bonded retainer.

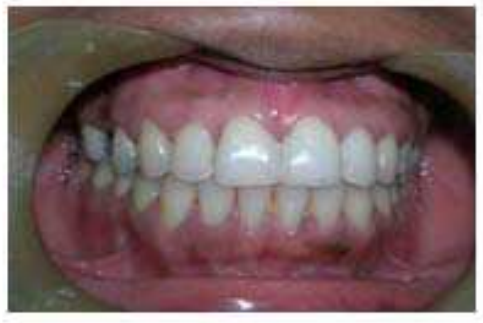

Fig 5(A)

Fig 5(A): Aesthetic approach : Case treated with direct restorative material :

Pre-treatment photograph. 